\title{
Field data for "acceptable" frequency of repetitive task: data to support standardization work
}

Emmanuelle Turpin-Legendre, Jean-Pierre Meyer INRS (National Institute for Safety and Research), Vandoeuvre les Nancy, France Emmanuelle.turpin-legendre@inrs.fr

Keywords: Musculoskeletal disorders; Perceived fatigue; Limit value

\section{Introduction}

One way to reduce musculoskeletal disorders (MSD) is to reduce the movement frequency of the upper limb. Standards provide acceptable values of frequencies [1], but objective data to define an "acceptable" repetitive task are scarce.

A repetitive task with a number of technical actions (TA) below 40 is considered acceptable [1]. Do the perceived fatigue and heart rate (HR) data obtained in employees of six factories confirm this limit value?

\section{Method}

Six factories where handling light loads at a high frequency is common took part in this study. These factories were in the perfume, cutting meat, car assembly, wood furniture, car equipments and metalwork sectors. The repetitive task studied had to include a few technical actions and be executed without the employee walking more than 2 meters. 80 employees were questioned about their health, the difficulties of the task, the perceived fatigue and whether parts of the body were painful. A rating of perceived exertion (RPE) was requested [2] for each task. The movement frequency defined for each task and each employee was recorded. Movement frequency was calculated according the number of technical actions (TA) per minute, as suggested in the Standard EN 1005-5, (2007). Subjective evaluations and heart rate (HR) were used to assess the relative load of the task. Physical workload was determined from the working cardiac cost (WCC), which is the difference between the mean HR recorded during the work and the HR recorded at rest for $5 \mathrm{~min}$ sitting before the work. Data were recorded over 8 hours.

\section{Result - Discussion}

Table 1 shows the working cardiac cost and the rating of perceived exertion as a function of the number of technical actions per minute and the duration of the task.

Table 1

Working Cardiac Cost (WCC) and Rating of Perceived Exertion (RPE) data as a function of the number of technical actions per minute (TA) and duration of the task. n: number of employees

\begin{tabular}{|l|l|l|l|l|}
\hline Task duration & WCC & RPE & TA & n \\
\hline$\leq 1$ hour & $19 \pm 10$ & $13 \pm 3$ & $51 \pm 18$ & 25 \\
\hline $1<$ hour $\geq 2$ & $16 \pm 6$ & $13.5 \pm 2$ & $33 \pm 11$ & 17 \\
\hline $2<$ hour $\geq 3$ & $18 \pm 7$ & $13 \pm 2$ & $36 \pm 7$ & 13 \\
\hline $3<$ hour $\geq 4$ & $14 \pm 5$ & $13 \pm 2$ & $40 \pm 13$ & 13 \\
\hline$\geq 4$ hour & $18.5 \pm 7$ & $11 \pm 3$ & $44 \pm 11$ & 10 \\
\hline
\end{tabular}


According to the references (NF EN 1005-5, 2007), a repetitive task with a number of TA per minute greater than $40 \mathrm{TA}$ corresponds to an unacceptable work situation. In this study, WCC and RPE characterize the work like "somewhat hard" with a number of technical actions over $40 \mathrm{TA}$. The static work carried out by the upper limbs can explain that the WCC data does not show physical workload. More surprising is employees feel no difficulties maintaining a high frequency of work whatever the duration of the task. Job rotation and breaks in the supply chain could explain these results. Employees did not work more than 2 hours continuously on the same task and rotations were sometime of $1 / 2$ hour or 1 hour for highly repetitive tasks. Regarding these field data, it could be interesting to compare them with other field data in standardization groups.

\section{Conclusion}

Keeping work below the limit of unacceptable movement frequency can help to reduce MSD. With field data of this study, it could be interesting to discuss the limit value for acceptable frequency, especially with job rotations requiring specific working times.

These data will be submitted to standardization groups to reinforce the present proposals with experimental results.

\section{References}

[1] NF EN 1005-5 (2007) - Safety of machinery - Human physical performance - Part 5 : Risk assessment for repetitive handling at high frequency. AFNOR.

[2] Borg, G., (1998). Borg's perceived exertion and pain scale. USA, Human Kinetics, vol.1, 112 p 